\title{
How Coronavirus (COVID-19) has made the Invisible Silent Killer of Air Pollution Visible: Lessons for Building Resilient Communities
}

\author{
Nana O Bonsu ${ }^{1 *}$, Francis Pope ${ }^{2}$, Martin Oteng Ababio ${ }^{3}$, Emmanuel Appoh ${ }^{4}$, Mary E Ashinyo ${ }^{5}$, \\ Stephen N Essuman ${ }^{6}$, Louise CS Donkor ${ }^{7}$ and Ian Thomson ${ }^{8}$ \\ ${ }^{1}$ Centre for Responsible Business, Birmingham Business School, UK \\ ${ }^{2}$ School of Geography, Earth and Environmental Sciences, UK \\ ${ }^{3}$ Department of Geography and Resource Development, University of Ghana \\ ${ }^{4}$ Environmental Protection Agency, Ghana \\ ${ }^{5}$ Ghana Health Service, Ghana \\ ${ }^{6}$ Land Use \& Spatial Planning Authority, Ghana \\ ${ }^{7}$ SDGs Advisory Unit at the Presidency, Ghana \\ ${ }^{8}$ Centre for Responsible Business, Birmingham Business School, University of Birmingham, UK \\ *Corresponding author: Nana Bonsu, Centre for Responsible Business, Birmingham Business School, University of Birmingham, \\ UK
}

\begin{tabular}{|c|c|}
\hline ARTICLE INFO & Abstract \\
\hline Received: 蔧 May 11, 2020 & Citation: Nana O B, Francis P, Martin Oteng A, Emmanuel A, Mary E A, et al., How \\
\hline Published: 㗀 June 01, 2020 & $\begin{array}{l}\text { Coronavirus (COVID-19) has made the Invisible Silent Killer of Air Pollution Visible: } \\
\text { Lessons for Building Resilient Communities. Biomed J Sci \& Tech Res 28(1)-2020. } \\
\text { BJSTR. MS.ID.004587. }\end{array}$ \\
\hline
\end{tabular}

\section{Covid-19 versus Air Quality}

In the battle to slow the spread of COVID-19, countries around the world are restricting social gatherings, encouraging working from home, closing schools and restricting public events. As a result, this brutal pandemic has inadvertently made the invisible and silent killer of air pollution now visible. After just a few weeks of these short-term lockdown measures restricting people and vehicular movement, there has been an observable and drastic reduction in traffic and air pollution in major urban cities within both the northern and southern hemispheres. In fact, globally, exposure to poor air quality contributes to 4.2 million deaths, whilst 98\% of cities in Low Medium Income Countries (LMICs) do not meet World Health Organisation (WHO) air quality standards.

\section{Case Study}

For instance, in Ghana, West Africa, where there is an ongoing research sandpit that uses real-time low-cost air-monitoring

sensors, pollution levels at a traffic hotspot in the capital Accra fell by unprecedented levels during coronavirus lockdown period. But pollution levels are rising to pre-pandemic levels ever since the lockdown restrictions was lifted (Figure 1). Funded by The Institute for Global Innovation (IGI) and Institute of Advanced studies, and partnering with University of Ghana, Department of Geography and Resource Development, including other government bodies, such as the Environmental Protection Agency and Ghana Health Service, the study aims to explore air pollution health impacts and monitor in real-time the levels of key toxic pollutants, such as nitrogen dioxide $\left(\mathrm{NO}_{2}\right)$, ozone $\left(\mathrm{O}_{3}\right)$ and particulate matter $\left(\mathrm{PM}_{2.5}\right.$ and $\left.\mathrm{PM}_{10}\right)$ in major Ghana's cities. Air pollution is responsible for over 28,000 premature deaths every year in Ghana, with regulatory measures to robustly tackle air pollution still lacking - just as they are in other major world economies, including the UK, Europe and US. Many of the pre-existing health conditions - such as cardiovascular disease 
and asthma - that dramatically elevate the risk of complications and death from COVID-19 are well known to be caused by longterm exposure to high concentrations of toxic air pollutants. Thus, people with pre-existing conditions living or working in more polluted cities are particularly at risk of respiratory problems or being hospitalised by COVID-19. New studies, including one from Harvard University, also link air pollution to significantly higher rates of death in people with COVID-19.

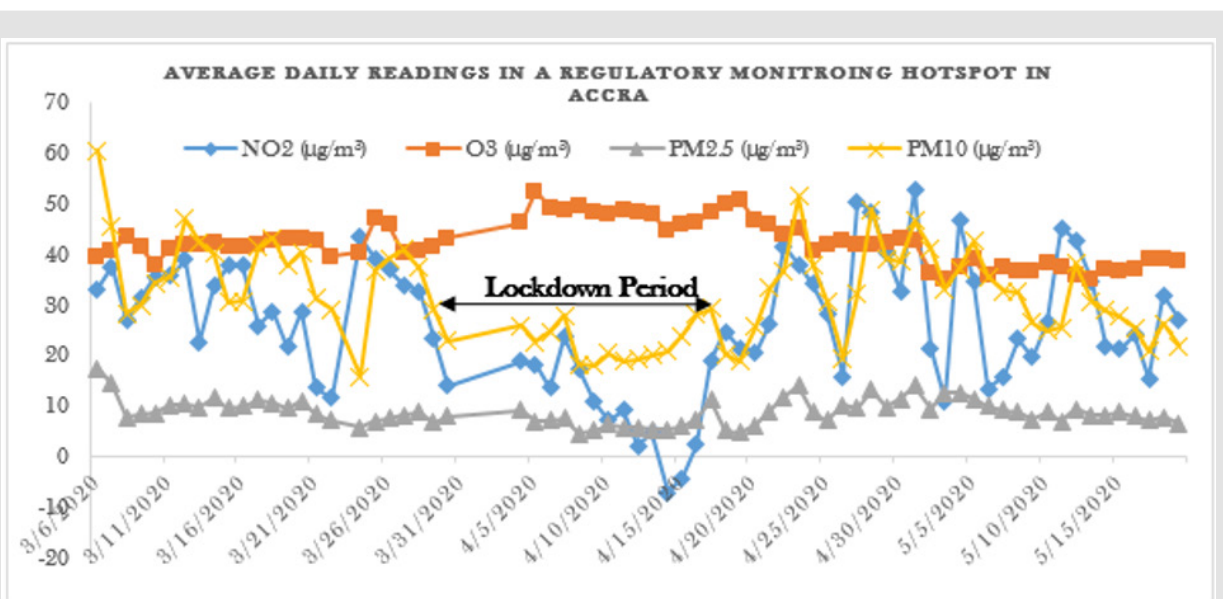

Figure 1: Interestingly, the amount of ozone $\left(\mathrm{O}_{3}\right)$ pollutant, has barely decreased compared with levels of other pollutants such as nitrogen dioxide $\left(\mathrm{NO}_{2}\right)$, and particulate matter (PM2.5 and PM10). Ground-level ozone occurs when the chemicals emitted by cars and trucks and other sources react with sunlight and heat. Ozone pollution is especially detrimental to children and elderly people and those with asthma and other respiratory illnesses.

\section{Conclusion}

The Covid-19 pandemic has crystallised how fragile and interconnected the world is, with socio-economic inequality being on full display, as poor air quality exacerbates existing health inequalities, especially amongst socially disadvantaged groups that are disproportionately exposed to air pollution. This correlation between the COVID-19 mortality and morbidity rate and poor air quality shows the urgency for policymakers to start discussing 'cleaner air for all' and reboot efforts once the pandemic is over. The results clearly show that improving air quality will take much more than cleaning up tailpipes of passenger cars. Like many government and World Health Organisation public messages and actions for COVID-19 prevention and control, such as physical distancing and washing your hands for 20 seconds, couldn't there be similar messages and actions for how to breathe and maintain cleaner air? After all, clean air is also key to 'flattening the curve' of thousands of premature deaths each year. And while avoiding a post-pandemic recession is important, this is not the time to start

ISSN: $2574-1241$

DOI: $10.26717 /$ BJSTR.2020.28.004587

Nana 0 Bonsu. Biomed J Sci \& Tech Res

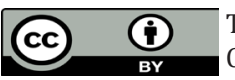

This work is licensed under Creative Commons Attribution 4.0 License

Submission Link: https://biomedres.us/submit-manuscript.php relaxing environmental pollution rules on struggling businesses and economies.

A jump-started economy that continues to choke so many people to death from air pollution is suboptimal in 'flattening mortality curve' - and not healthy for anyone. We cannot afford to return to a pre-pandemic 'business as usual' scenario. Policymakers should be looking to strengthen urban air quality and environmental emissions regulations to maintain the lower pollution levels of recent weeks. Crucially, authorities with power at the (national and local levels) also need to take into account issues of social vulnerability and the disparity in the vulnerable, disadvantaged or poorer people's access to power, knowledge and resources. Only by policymakers risking their political values and philosophy, to deal with 'the politics of disadvantage' and make better socio-environmental quality a key building block of local community planning, can we hope to create more equitable and resilient societies that will be better future proofed against any resurgence of the virus or another global shock.

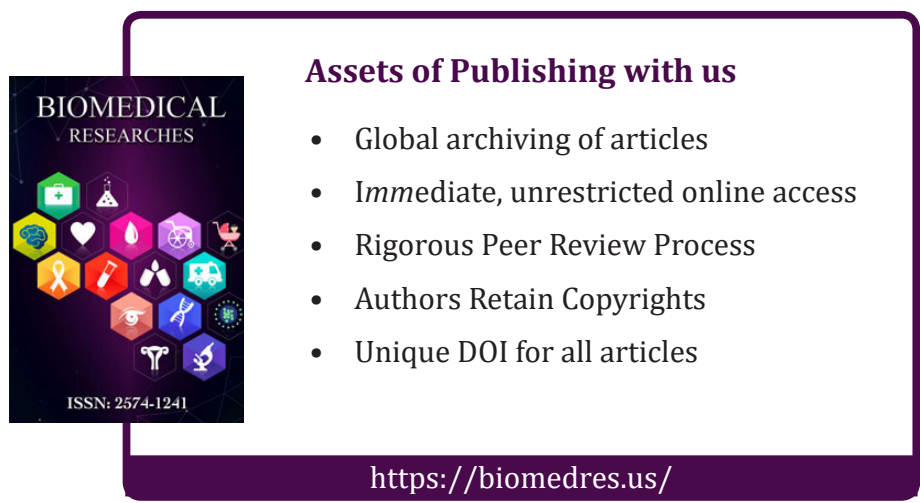

Copyright@ Nana O Bonsu | Biomed J Sci \& Tech Res | BJSTR. MS.ID.004587. 